\title{
Pulmonary embolism associated with oral contraceptive use - Case report
}

\author{
Agnieszka Witczak', Andrzej Prystupa', Jerzy Mosiewicz \\ ${ }^{1}$ Department of Internal Medicine, Medical University of Lublin, Poland \\ Witczak A, Prystupa A, Mosiewicz J. Pulmonary embolism associated with oral contraceptive use - Case report. J Pre-Clin Clin Res. 2014; \\ 8(2): 120-122. doi: 10.5604/18982395.1135664
}

\begin{abstract}
A 25-year-old female patient with a history of oral contraceptive use was admitted to hospital because of exertional dyspnoea, palpitations, chest discomfort and weakness. Since the clinical presentation was suggestive of some heart disease the patient underwent echocardiography which revealed indirect signs of acute pulmonary embolism. The diagnosis was confirmed with multisliced computed tomography of the pulmonary arteries. Blood test results raised suspicion of antithrombin III deficiency. Enoxaparin and warfarin were used as treatment regimen with good effect and the patient was discharged home without significant symptoms, signs, and with normal echocardiography.
\end{abstract}

\section{Key words}

pulmonary embolism, contraceptive use, antithrombin III deficiency

\section{CASE REPORT}

A 25-year-old female patient was admitted to hospital because of exertional dyspnoea, palpitations, chest discomfort and weakness. The symptoms had started about three weeks prior to hospital admission. The patient's medical history was negative for significant disorders but the patient declared prolonged use of oral contraceptives. On physical examination, increased resting heart rate of about 140 per minute was found. ECG revealed sinus tachycardia without other abnormalities. The patient fainted and became pale in the face when trying to move from the bed. Since the clinical presentation was suggestive of some heart disease the patient underwent bedside echocardiography, and blood samples were taken for laboratory tests, including troponin $\mathrm{T}, \mathrm{N}$-terminal of the prohormone brain natriuretic peptide (NT-proBNP) and D-dimer level. On echocardiography, indirect signs of acute pulmonary embolism were found including McConnell's sign, dilatation of the right ventricle, shortening of pulmonary artery acceleration time with a typical notch on the spectrum, tricuspid regurgitation with TRVPG (tricuspid regurgitation peak gradient) about 70 mmHg. D-dimer level and NT-proBNP level were elevated. Troponin $\mathrm{T}$ level remained within normal range. Laboratory findings are shown in Table 1. The patient was sent for multisliced computed tomography of the pulmonary arteries and large clots were found within both branches of the main pulmonary artery (Fig. 1).

Based on imaging, blood test results and clinical presentation, intermediate-risk pulmonary embolism was diagnosed in the patient. Pulmonary embolism is a rare disorder in young individuals without known risk factors for venous thromboembolism. Therefore, a blood sample was also taken for diagnosis of possible thrombophilia, including evaluation of antithrombin III, mutation of factor V Leiden, prothrombin, protein C, protein S and factor VIII. The level of antithrombin III was slightly lowered to about $77 \%$ of

Address for correspondence: Andrzej Prystupa, Department of Internal Medicine, Medical University, Lublin, Poland

E-mail: aprystup@mpl

Received: 04 September 2013; accepted: 29 May 2014
Table 1. Laboratory characteristics of the patient

\begin{tabular}{lcc}
\hline \multicolumn{1}{c}{ Parameter } & Value & Reference range \\
\hline $\mathrm{Hb}$ & $14.1 \mathrm{~g} / \mathrm{dl}$ & $12-16 \mathrm{~g} / \mathrm{dl}$ \\
\hline $\mathrm{D}-$ dimer on admission & $7969.36 \mathrm{ngFEU} / \mathrm{ml}$ & $<500 \mathrm{ngFEU} / \mathrm{ml}$ \\
\hline $\mathrm{D}-$ dimer on discharge & $1432.82 \mathrm{ngFEU} / \mathrm{ml}$ & \\
\hline $\mathrm{TnT}$ & $0.03 \mathrm{ng} / \mathrm{ml}$ & $<0.03 \mathrm{ng} / \mathrm{ml}$ \\
\hline $\mathrm{Na}$ & $142 \mathrm{mmol} / \mathrm{l}$ & $136-145 \mathrm{mmol} / \mathrm{l}$ \\
\hline $\mathrm{K}$ & $4.38 \mathrm{mmol} /$ & $3.5-5.1 \mathrm{mmol} / \mathrm{l}$ \\
\hline $\mathrm{CRP}$ & $28.9 \mathrm{mg} / \mathrm{dl}$ & $0-5 \mathrm{mg} / \mathrm{dl}$ \\
\hline TSH & $0.356 \mathrm{uU} / \mathrm{ml}$ & $0.27-4.2 \mathrm{uU} / \mathrm{ml}$ \\
\hline Glucose & $97.5 \mathrm{mg} / \mathrm{dl}$ & $60-100 \mathrm{mg} / \mathrm{dl}$ \\
\hline Creatinine & $0.5 \mathrm{mg} / \mathrm{dl}$ & $0.6-1.1 \mathrm{mg} / \mathrm{dl}$ \\
\hline NT-proBNP on admission & 6487 & $<300 \mathrm{pg} / \mathrm{ml}$ \\
\hline NT-proBNP on discharge & 65 & $<125 \mathrm{pg} / \mathrm{ml}$ \\
\hline
\end{tabular}

normal value. Since the patient was stable without signs or symptoms of haemodynamic compromise, low molecular weight heparin - enoxaparin - at a weight-adjusted dose of $1 \mathrm{mg} / \mathrm{kg}$ was administered subcutaneously twice daily. The patient's state improved significantly within two days. After five days, the patient was administered orally the anticoagulant warfarin. No recurrent dyspnoea, fainting or bleeding as a side-effect of the treatment were observed. Echocardiographic measures as well as laboratory findings of heart failure returned to normal. The patient was discharged home safely with recommendation to keep taking warfarin for at least six months and to repeat antithrombin III level evaluation after the treatment. This was because the low values observed in the acute stage of the disease could be the result of ongoing thrombosis.

\section{DISCUSSION}

Although venous thromboembolism (VTE) has been observed, the uncommon disorder of pulmonary embolism (PE) in women before menopause remains one of the most common causes of sudden death among apparently young 

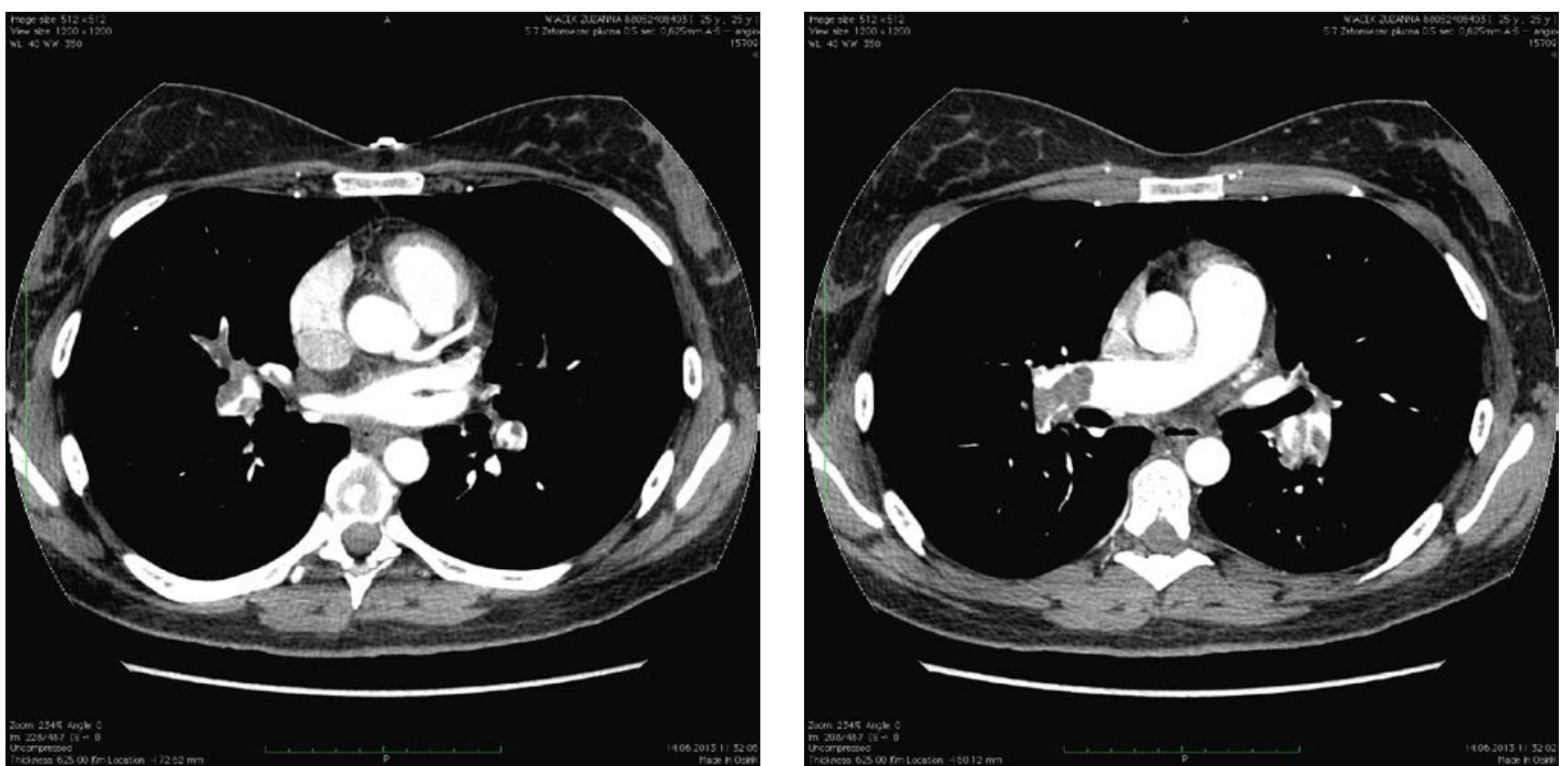

Figure 1. Multisliced computed tomography of pulmonary arteries with large clots within both branches of the main pulmonary artery

healthy women, especially during pregnancy and the postpartum period $[1,2]$. The absolute risk of pulmonary embolism is low among this population, but it must be emphasised that the group affected are young healthy persons [3]. Combined oral contraceptives were long ago reported to induce VTE $[4,5,6]$, the most important determinant of the benefit/ risk profile of contraceptives [7]. With their use, the risk of VTE may increase six times compared to non-users, making the relative risk of thromboembolic complications high [8]. There are reports concerning about one half of cases of VTE in young women of reproductive age related to the use of oral contraceptives [9]. Deep vein thrombosis (DVT) was reported in $60 \%$ and pulmonary embolism in $30 \%$ of contraceptive users aged from 18 - 49 [3]. In 59\% of survivors, a permanent post-embolic residual deficit of lung perfusion was found on imaging [10]. The highest risk of thrombosis is typical for the first year of contraceptive use. The type of progestogen and dose of oestrogen are mostly responsible for the increase in thrombotic risk, and levonorgestrel with a low dose oestrogen seems to be the safest agent. About 60\% of women aged 16-30 use oral contraceptives containing ethinylestradiol and progestogen [11]. Oestrogens raise the levels of factors II, VII, VIII and X as well as induce activated protein $\mathrm{C}$ resistance. Some progestins may increase the oestrogen-induced activated protein $C$ resistance [12]. The fibrinolytic potential is decreased in oral contraceptive users [13].

Few data are available about the characteristics of patients who experience the first episode of VTE during contraceptive use. Cigarette smoking, overweight and a positive family history for DVT were common among affected individuals [8]. In $50 \%$ of the affected individuals trombophilias were found with AT III deficiency in about $1 \%$ of cases [14]. Use of Combined Oral Contraception (COC) is common in athletic women since the agents enhance physical capacity [15]. Female athletes have no such risk factors as obesity, immobility and cigarette smoking, therefore the risk of VTE is lower in this population of COC users. Clinical presentation of pulmonary embolism may be nonspecific in COC users, including pain in the paracostal low back and scapular region, as well as cough (16). The risk of VTE returns to normal after discontinuation of the treatment $[17,3]$. Before COCs are prescribed, counselling on sideeffects, including VTE, is mandatory as well as careful evaluation of risk factors for VTE and screening for other abnormalities, including hypertension, obesity, cigarette smoking and positive family history for spontaneous VTE is recommended [17]. In the case of previous VTE, COCs are either contraindicated or, as in the case of persons with risk factors for VTE, including thrombophilia, progestogen-only contraception may be an option [6]. Thrombophilia is the predisposition to form clots inappropriately. The abnormality may result in thrombotic disorders in young, apparently healthy individuals [18]. Inherited thrombophilias have been found in about $30 \%$ of patients with pulmonary embolism, for which there are different guidelines on screening [19]. In the case of pulmonary embolism in a young individual below 50 years of age, without any known risk factors, such as immobilisation, surgery, malignancies, screening for thrombophilias is recommended including mutation of factor V Leiden, prothrombin, antithrombin III, protein C, protein $S$, factor VIII and activated protein C resistance [20]. The use of oral contraceptives may induce pulmonary embolism in patients with inherited thrombophilias [14].

The patient in the presented case was found to have a low level of AT III on initial evaluation. Antithrombin is a glycoprotein that inhibits the action of thrombin and activated factor $\mathrm{X}$. Low serum antithrombin may result either from congenital deficiency or other disorders, including liver disease, sepsis, or major surgery. Inherited antithrombin deficiency is a rare but the most severe type of thrombophilia associated with extreme risk of thromboembolism, especially of venous origin, as well as pregnancy loss [15]. Deep vein thrombosis due to AT deficiency may affect both the peripheral veins, including extremities, brain, liver and mesentery, as well as result in pulmonary embolism. Most cases are heterozygous and males and females are equally affected [14, 15]. The deficiency may be either quantitive - but it is not 
known whether the degree of AT decrease reflects the risk of thrombosis, or qualitive - resulting from abnormalities of the thrombin-binding site [21]. AT deficiency may result in 1.9-fold higher risk of VTE [22]. There are reports of cases of pulmonary embolism in individuals with AT activity of about $50 \%$ of normal values [23]. Primary prevention is not recommended in this population because the risk of thromboembolism is low compared with the high risk of possible bleeding complications of anticoagulation [15]. Symptomatic patients with AT III deficiency are candidates for prolonged anticoagulation [22].

\section{REFERENCES}

1. Guidelines on the diagnosis and treatment of pulmonary embolism. Task Force for the Diagnosis and Management of Acute Pulmonary Embolism of the European society of Cardiology. Eur Heart J. 2008; 29: 2276-2315

2.Plu-Bureau G, Maitrot-Mantelet L, Hugon-Rodin J, Canonico M. Hormonal contraceptives and venous thromboembolism: an epidemiological update. Best Pract Res Clin Endocrinol Metab. 2013; 27(1): 25-34.

3. Dinger JC, Heinemann LA, Kühl-Habich D. The safety of a drospirenonecontaining oral contraceptive: final results from the European Active Surveillance Study on oral contraceptives based on 142,475 womenyears of observation. Contraception. 2007; 75(5): 344-354.

4.van Hylckama Vlieg A, Helmerhorst FM, Vandenbroucke JP, Doggen CJ, Rosendaal FR. The venous thrombotic risk of oral contraceptives, effects of oestrogen dose and progestogen type: results of the MEGA case-control study. BMJ. 2009; 339: 2921.

5. Gronich N, Lavi I, Rennert G. Higher risk of venous thrombosis associated with drospirenone-containing oral contraceptives: a population-based cohort study. CMAJ. 2011; 183(18): 1319-1325.

6. Lidegaard $\varnothing$, Løkkegaard E, Svendsen AL, Agger C. Hormonal contraception and risk of venous thromboembolism: national followup study. BMJ. 2009; 339: 2890.

7.Heinemann LA, Dinger JC, Assmann A, Minh TD. Use of oral contraceptives containing gestodene and risk of venous thromboembolism: outlook 10 years after the third-generation "pill scare". Contraception 2010; 81(5): 401-407.

8. Vaillant-Roussel H, Ouchchane L, Dauphin C, Philippe P, Ruivard M. Risk factors for recurrence of venous thromboembolism associated with the use of oral contraceptives. Contraception 2011; 84(5): 23-30.

9.Dinger J, Assmann A, Möhner S, Minh TD. Risk of venous thromboembolism and the use of dienogest- and drospirenonecontaining oral contraceptives: results from a German case-control study. J Fam Plann Reprod Health Care. 2010; 36(3): 123-129.
10. Chroustova D, Kubinyi J, Jansa P, Veprekova L, Trnka J. V/P scan in diagnosis and follow-up of pulmonary embolism in 15-25-year-old females in relation to hormonal contraception use. Nucl Med Rev Cent East Eur. 2011; 14(2): 63-67.

11. Rott H. Thrombotic risks of oral contraceptives. Curr Opin Obstet Gynecol. 2012; 24(4): 235-240.

12. Khan S, Smulders YM, de Vries JI, Spoelstra-de Man AM. Lifethreatening complications of hormonal contraceptives: a case history. Case Rep Obstet Gynecol. 2013; 186-230.

13. Klipping C, Duijkers I, Parke S, Mellinger U, Serrani M, Junge W. Hemostatic effects of a novel estradiol-based oral contraceptive: an open-label, randomized, crossover study of estradiol valerate/dienogest versus ethinylestradiol/levonorgestrel. Drugs R D. 2011; 11(2): 159-170.

14. Legnani C, Palareti G, Guazzaloca G, Cosmi B, Lunghi B, Bernardi F, Coccheri S. Venous thromboembolism in young women; role of thrombophilic mutations and oral contraceptive use. Eur Heart J. 2002; 23(12): 984-990.

15. Patnaik MM, Moll S. Inherited antithrombin deficiency: a review. Haemophilia 2008; 14(6): 1229-1239.

16. Landesberg WH. Pulmonary embolism in a female collegiate crosscountry runner presenting as nonspecific back pain. J Chiropr Med. 2012; 11(3): 215-220.

17. Martínez F, Ramírez I, Pérez-Campos E, Latorre K, Lete I. Venous and pulmonary thromboembolism and combined hormonal contraceptives. Systematic review and meta-analysis. Eur J Contracept Reprod Health Care. 2012; 17(1): 7-29.

18. Lenicek Krleza J, Jakovljevic G, Bronic A, Coen Herak D, Bonevski A, Stepan-Giljevic J, Roic G. Contraception-related deep venous thrombosis and pulmonary embolism in a 17-Year-old girl heterozygous for factor V Leiden, prothrombin G20210A mutation, MTHFR C677T and homozygous for PAI-1 mutation: report of a family with multiple genetic risk factors and review of the literature. Pathophysiol Haemost Thromb. 2010; 37(1): 24-29.

19. Turan O, Ündar B, Günay T, Akkoçlu A. Investigation of inherited thrombophilias in patients with pulmonary embolism. Blood Coagul Fibrinolysis. 2013; 24(2): 140-149.

20. Ivanov P, Komsa-Penkova R, Kovacheva K, Ivanov Y, Stoyanova A, Ivanov I, Pavlov P, Glogovska P, Nojarov V. Impact of thrombophilic genetic factors on pulmonary embolism: early onset and recurrent incidences. Lung 2008; 186(1): 27-36.

21. Maclean PS, Tait RC. Hereditary and acquired antithrombin deficiency: epidemiology, pathogenesis and treatment options. Drugs 2007; 67(10): 1429-1440.

22. De Stefano V, Simioni P, Rossi E, Tormene D, Za T, Pagnan A, Leone G. The risk of recurrent venous thromboembolism in patients with inherited deficiency of natural anticoagulants antithrombin, protein C and protein S. Haematologica 2006; 91(5): 695-698.

23. Takahashi J, Ito M, Okude J, Gohda T, Wakamatsu Y, Sasaki S, Yasuda K. Pulmonary thromboembolectomy in congenital antithrombin III deficiency associated with acute pulmonary embolism - report of a case. Ann Thorac Cardiovasc Surg. 2003; 9(3): 192-196. 